\title{
BMJ Open A qualitative study of the consequences of knee symptoms: 'It's like you're an athlete and you go to a couch potato'
}

\author{
Crystal MacKay, ${ }^{1,2,3}$ Susan B Jaglal,, ${ }^{3,4,5}$ Joanna Sale, ${ }^{4,6}$ Elizabeth M Badley, ${ }^{1,7}$ \\ Aileen M Davis ${ }^{1,2,3,4}$
}

To cite: MacKay C, Jaglal SB, Sale J, et al. A qualitative study of the consequences of knee symptoms: 'It's like you're an athlete and you go to a couch potato'. BMJ Open 2014;4:e006006. doi:10.1136/bmjopen-2014006006

- Prepublication history for this paper is available online. To view these files please visit the journal online (http://dx.doi.org/10.1136/ bmjopen-2014-006006)

Received 30 June 2014 Revised 22 August 2014 Accepted 1 September 2014

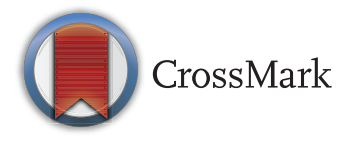

For numbered affiliations see end of article.

Correspondence to Crystal MacKay;

cmackay@uhnres.utoronto.ca

\section{ABSTRACT}

Objectives: To explore the perceived consequences of knee symptoms on the lives of people aged 35-65 years who had diagnosed osteoarthritis $(\mathrm{OA})$ or $\mathrm{OA}$-like symptoms.

Design: A qualitative study with six focus groups and 10 one-on-one interviews. Constructivist grounded theory guided data collection and analysis. Data were analysed using the constant comparative method.

Setting: Toronto, Canada.

Participants: 51 participants (median age 49; 61\% female) who self-reported knee OA or reported knee pain, aching or stiffness on most days of the past month participated in the study.

Results: The core finding, disruption and change, illustrates the range of perceived consequences of knee symptoms in peoples' lives. Participants described the consequences of symptoms on their physical activity (giving up high-level activities or changing how or how much they performed activities), social life (leisure, family and work) and emotional life. Knee symptoms also altered the way participants thought about their bodies and themselves. They reported that they had a new awareness of their knee and that they no longer trusted their knee. They also conveyed that their sense of self was altered.

Conclusions: This study illuminates the significant and varied consequences that mild to moderate knee symptoms have on the lives of adults age 35-65 years. Findings highlight the need for clinicians to tailor advice and support to the individual's needs considering their symptoms, the consequences of symptoms on their lives and their personal context.

\section{INTRODUCTION}

Osteoarthritis (OA) is a common chronic condition resulting in pain, fatigue, functional limitations, increased healthcare utilisation and high economic costs to society. ${ }^{1-6}$ The burden of OA is projected to increase, due in part to obesity and population aging. ${ }^{7-9}$ While the prevalence of $\mathrm{OA}$ increases with age, ${ }^{10} 11$ there is a growing recognition that OA affects people at younger

\section{Strengths and limitations of this study}

- The consequences of knee symptoms in younger adults have been largely neglected. The major strength of the study is that it uses participants' perspectives to understand the consequences of knee symptoms in adults age 35-65 years. Participants experienced disruption in their physical, social and emotional life and changes in how they thought about their body and self. In addition to the immediate effects, these consequences could have long-term effects on participants' health and well-being as they age.

- Findings have implications for practice, highlighting the need for approaches in the healthcare system or community which support the diverse needs of individuals in the context of their lives. In particular, support is needed to help people remain physically active by appropriately modifying their actions when needed and by facilitating exercising in ways that prevent excessive joint stress.

- We used a self-report diagnosis of osteoarthritis (OA) or knee symptoms and were unable to confirm if people had OA. However, we based our joint symptoms question on a widely used survey question on joint pain and carefully selected exclusion criteria to recruit participants more likely to have $\mathrm{OA}$.

ages. Recent US data demonstrated that half of people with symptomatic knee OA are diagnosed by age $55 .^{11}$ Healthcare systems are dealing with the increasing rates of total joint replacement (TJR) for younger patients, particularly those aged 45-64. ${ }^{12} 13$ There are calls for a paradigm shift in OA management to focus on persons at high risk of developing, or with, early disease in which structural changes may be preventable or reversible. ${ }^{1415}$ Screening and treating people earlier may help to alter disease progression and reduce the considerable costs to the healthcare system. ${ }^{15}$ To facilitate earlier intervention, a greater emphasis on disease prevention and management in younger adults 
is critical. A prerequisite to delivering accessible and acceptable care is an understanding of the effects of disease on people's everyday lives. ${ }^{16}$ As such, an important first step in developing effective interventions to support early management in younger adults is understanding the consequences of knee symptoms on peoples' lives.

Research has shown that living with chronic illness leads to a variety of consequences and has highlighted the need to put the subjective experience of the patient at center stage. ${ }^{17-21}$ Studies of different chronic illnesses have also shown that the experience of chronic illness varies by age. ${ }^{20-22}$ Research in OA has focused largely on older persons with end stage disease. ${ }^{21}{ }^{23}$ Studies in older adults with $\mathrm{OA}$ have highlighted the disruptive nature of symptoms in people's daily life including functional limitations and psychological distress. ${ }^{21}{ }^{23}$ The consequences of $\mathrm{OA}$ in younger adults have been largely neglected. One study of younger Taiwanese adults with knee OA reported that people experienced difficulties with exercise and a reduction of work. ${ }^{24}$ However, there is a general lack of understanding of how OA symptoms affect younger people in their daily lives. The consequences of symptoms in younger adults may be underappreciated given $\mathrm{OA}$ is often perceived to be a disease of older people, even by healthcare providers. ${ }^{15}{ }^{25}$ As such, it remains unclear how best to provide effective and relevant support earlier in life. This study aimed to fill this gap and explore the perceived consequences of knee symptoms on the lives of people aged 35-65 years who had diagnosed knee OA or symptoms that were consistent with knee OA. Since not all participants had a diagnosis of OA, we use the term knee symptoms rather than $\mathrm{OA}$ when describing the study.

\section{MATERIALS AND METHODS}

\section{Study design}

This study used qualitative methods, comprising focus groups and one-on-one interviews. While this work explored the consequences of knee symptoms, it is part of a broader study exploring the perceptions, experiences and management of knee symptoms. The methods for conducting these focus groups have been described elsewhere. ${ }^{26}$ The principles and methods of constructivist grounded theory guided data collection and analysis. ${ }^{27}{ }^{28}$ This approach seeks to understand the participants' beliefs and actions from their perspectives and views researchers as cocreators of the data. This study drew on symbolic interactionism, a theoretical perspective which provided underpinning for grounded theory and posits that people construct selves, society and reality through social interaction with others. ${ }^{27} 28$

\section{Sampling and data collection}

Participants were recruited from advertisements in a community paper, an acute care hospital and community centres in the Greater Toronto Area. ${ }^{26}$ Individuals were included if they were aged 35-65 and self-reported a diagnosis of knee OA or reported that they had knee symptoms (ie, pain, aching or stiffness) on most days of the past month, recognising that younger adults may not have a diagnosis or perceive their symptoms to be OA. Participants who had a knee injury, knee pain referred from the low back, other types of arthritis (eg, inflammatory arthritis), who were waiting for, recommended or had undergone TJR or who had other chronic physical health conditions (eg, stroke) that affected their mobility were excluded. People who were waiting for TJR were excluded as they are more likely to have end stage OA with substantial pain and disability. Sampling was purposive, initially seeking variation across age and sex. As data collection and analysis progressed, we continued to seek variation in age to explicate the categories being developed. Data collection continued until the team came to a consensus that saturation was reached. ${ }^{29}$

Multiple sources of data have been recommended in qualitative research. ${ }^{30}$ We used focus groups and interviews as research has shown that focus groups are useful at examining the range of participants' experiences, while individual interviews contribute to the detailing of experiences. ${ }^{30}$ First, six semistructured focus groups $(n=41)$ were conducted in hospital boardrooms. Participants were grouped by age (35-49 years and 50-65 years) to create homogeneous groups. The first author moderated the focus groups while a second individual kept a speaker $\log$ and took notes summarising verbal and non-verbal communication. A focus group guide facilitated discussions (box 1). Participants were encouraged to share their experiences, even if they differed from others' experiences. Discussion among the group (eg, questioning one another and commenting on others' experiences) was encouraged and facilitated by the moderator. For instance, the moderator would ask the group, "Has anyone else had a similar or different experience?" Following the focus groups, 10 semistructured interviews were conducted with new participants at the hospital or the participant's workplace. The focus group guide was refined for the interviews based on preliminary analyses (box 1). The first author conducted all interviews and used prompts to clarify or elaborate responses. Focus groups lasted 1.5-2 $\mathrm{h}$ and interviews lasted approximately $1 \mathrm{~h}$. Field notes were written following each focus group/interview to summarise data and reflect on analytic topics being developed.

All focus groups/interviews were audio recorded, transcribed verbatim and entered into a qualitative software program, NVivo9, to facilitate data management and analysis. Participants completed the Knee Injury and Osteoarthritis Outcome Score (KOOS) to describe the extent of participants' symptoms and function. KOOS scores ranged from 0 to 100 for each subscale (100 indicated no symptoms, 0 indicated extreme symptoms). ${ }^{32}$

\section{Analysis}

A constant comparative analysis was used, in which comparisons constituted each stage of analysis (eg, 


\section{Box 1 Question guides}

\section{Focus groups}

1. Tell me about what is happening with your knee(s).

2. We are interested in your experiences with your knee in your daily life. Can you tell me how your knee fits into your daily life?

3. When you think of yourself 10 or 20 years down the road, what do you think might happen with your knee?

4. What do you do for your knee?

5. After having your experience, what advice would you give someone else who has just started to have knee issues?

6. Do you have anything else you wish to say about living with your knee symptoms?

Interviews

1. Tell me about the problems you have been having with your knee(s).

2. How did your knee problems develop?

3. Has your knee changed things for you in your life? How?

4. What is your knee like on a day-to-day basis?

a) Tell me about a day when you don't require much from your knee.

b) Tell me about a day when you require a lot from your knee.

5. Tell me about how you feel about your knee?

6. Thinking about your knee, what do you think about the future?

7. Do you have anything else you wish to say related to your knee? Is there anything else you'd like to raise that we didn't talk about today?

comparing data with data, data with category, category with category). ${ }^{27}$ Data analysis was conducted concurrently with data collection to allow developing themes to be pursued in subsequent focus groups/interviews. The analysis had three main steps: open coding, axial coding and constructing a core category which explained the central theme of the data. ${ }^{33}$ The first author open coded the data and developed a coding scheme which was reviewed by all authors. Content of codes, including specific quotes, were presented and discussed at regular meetings and codes were subsequently further refined. The senior author read all transcripts and discussed interpretations of the data with the first author at regular meetings. All authors read the majority of the transcripts and met regularly to discuss the data and ongoing analysis, including alternate interpretations of the data. Use of a reflexive diary and group discussions also provided an opportunity to consider how the researchers' assumptions and beliefs might impact interpretation of data. Memos were written to make comparisons across data and explicate developing categories. Analysis included multiple readings of the transcripts to understand the consequences of knee symptoms in participants' lives.

This study integrated recommended principles to enhance quality in qualitative research ${ }^{31} 34$ including a systematic approach to designing, conducting and analysing the study, maintaining an audit trail (collection of study documentation including decision-making), a field diary to promote reflexivity and use of thick description (eg, in-depth illustration and abundant detail) and quotations. Strategies recommended for quality in grounded theory (concurrent data collection and analysis, constant comparative analysis, memoing) were also incorporated. ${ }^{27} 35$

\section{RESULTS}

Fifty-one individuals with moderately symptomatic OA based on KOOS scores $^{36}$ participated (table 1: demographics; table 2: KOOS scores). The core category is presented first, followed by a detailed description of the categories subsumed under the core category. Illustrative quotes are presented throughout the text and in box 2 (pseudonyms are used).

\section{Core category: disruption and change}

The core finding, disruption and change, illustrated the consequences of knee symptoms on peoples' lives (figure 1). Symptoms resulted in disruption and change in two main categories: (1) Disrupted physical, emotional and social life and (2) Altered way of thinking about the body and self. The first category referred to the disruption described by participants in three aspects of their lives: physical disruption (disruption in one's ability to carry out physical activities), emotional disruption and social disruption (disruption in social interactions and social roles in leisure/social activities, work and family life). In the second category, participants described three changes in the way they thought about their bodies and selves: a new awareness, lack of trust in their knee and an altered sense of self. Within each of the two main categories, consequences could influence

\begin{tabular}{ll}
\multicolumn{2}{l}{ Table 1 Sample demographics $(\mathrm{n}=51)$} \\
\hline Demographics & $\mathbf{N}(\%)$ \\
\hline Age & \\
Median & 49 \\
$\quad$ Minimum & 37 \\
Maximum & 65 \\
IQR & $(44,58)$ \\
Female & $31(60.8)$ \\
Education & \\
$\quad$ High school & $5(9.8)$ \\
$\quad$ Trades certificate/diploma or & $16(31.4)$ \\
$\quad$ college graduate & \\
$\quad$ University graduate & $30(58.8)$ \\
Marital status & \\
$\quad$ Married/living as married & $21(41.2)$ \\
$\quad$ Divorced/widowed/never married & $30(58.8)$ \\
Work & \\
$\quad$ Currently working & $40(78.4)$ \\
$\quad$ Unemployed & $7(13.7)$ \\
$\quad$ Retired & $3(5.9)$ \\
$\quad$ Student & $1(2.0)$ \\
Diagnosis of OA/OA-like symptoms & $26(51.0) / 25(49.0)$ \\
\hline OA, osteoarthritis. &
\end{tabular}


Table 2 Knee symptoms and function

\section{Knee osteoarthritis and outcome score} (subscales)

Scores*

Symptoms

$67.02(14.08)$

Pain

$63.69(18.01)$

$68.78(18.26)$

$52.05(27.86)$

Function in sport and recreation

Knee-related quality of life

$43.0(19.22)$

${ }^{*}$ KOOS scores ranged from 0 to 100 for each subscale; 100

indicated no symptoms, 0 indicated extreme symptoms.

each other. For example, physical disruption, such as giving up sports, could influence social disruption (eg, loss of social interactions). Moreover, consequences within one category could influence consequences in the other category (eg, social disruption could influence one's sense of self). Personal context (eg, gender, age, stage of life, social roles) shaped how people experienced consequences within their lives. Examples of the influence of personal context are provided within the following descriptions of the consequences of knee symptoms.

\section{Disrupted physical, social and emotional life Physical disruption}

A common consequence described by participants was the effect of symptoms on their physical activities. The physical disruption was varied and contingent on participants' symptoms and the role of physical activity in their lives. Some participants gave up demanding physical activities, such as soccer or running, which they often represented as a loss in their life. One participant who gave up running explained: "I ran almost seven days a week for a good ten years, pretty much $5 \mathrm{k}$ a day every day. And there's nothing more in the world that I like more than doing that... And to have it cut off like that..." (Mark, age 46, focus group 2). Others were able to maintain their physical activities, depending on the demands of the activity they valued participating in. Some participants struggled with whether and when to give up activities. For instance, some participants expressed concern for their knee but were unclear what activities they should avoid. Other participants wished they had given up activities they perceived had caused damage to their knee, such as running, 'collision' sports or squash, or changed activities earlier to prevent or reduce their current knee symptoms.

Whether or not participants gave up activities, most reported changes to how physical activities were performed, the amount of activity and/or the speed at which they performed the activity. Some participants reported being less active than they had been and that symptoms had 'slowed' them down. For example, Adam (age 54, interview) reported: "I may not be able to do them to the extent that I did do them before".
Participants reported varied reasons for the physical disruption in their lives. Some participants indicated that they gave up or changed their physical activity due to the symptoms, such as pain, that they experienced while doing the activity. Another reason some participants gave for changing physical activity was their perception that certain demanding physical activities, such as running, might cause further 'damage' or joint degeneration in their knee or even accelerate the need for surgery. James (age 42, interview) reported both of these reasons for changing his physical activities. While reflecting on his attempt to return to running, he recounted: "But I had too much pain, right away, so then I quickly stopped again". Later, when discussing why he turned down an invitation to do a long bike ride, he reflected: "I thought what possible further damage am I going to do long-term".

\section{Social disruption}

Changes in physical activities could also affect leisure and social life. Giving up activities (eg, squash, dancing) linked to social interactions was often represented as a social loss in their life. Some participants felt isolated from peers when they could not physically participate or keep up with friends. One participant explained: "I have a couple of girlfriends, who were walking regularly, and then I really hurt my knee bad and then I couldn't join them. I am socially isolated because of it" (Susan, age 47, interview). Participants who maintained activities or did not link social life to physical activity did not report such consequences.

Some participants discussed the repercussions of their knee symptoms on their family life. In particular, younger participants who were parents to young children described consequences of the symptoms on their role as a parent. They reported challenges playing with children on the floor or being active with their children. For example, Wilson (age 41, focus group 6) commented: "Most of us that have kids, having the problems with your knee are not able to get down on the ground to play with them".

While symptoms did not cause disruption at work for all participants, it did have significant consequences for some individuals, depending on the demands of the job. A couple of participants reported not working due to their symptoms. For example, one woman who worked in food services and retail stopped working due to difficulty with prolonged standing. More commonly, participants recounted changes at work. These often came in the form of modifications they made to reduce the disruption to work life, such as working from home, delegating activities or adapting their work environment.

\section{Emotional disruption}

Participants described a wide range of emotional responses to symptoms. While some participants expressed frustration and annoyance at having symptoms, others described feeling depressed by symptoms 
Box 2 Illustrative quotes by category

Disrupted Physical, Social and Emotional Life

Physical Disruption

I used to run, skipping, jumping. I used to play badminton, tennis. I used to be able to kick over my head. My mom wanted me to be a dancer; skinny, very physically active, constantly. And when that happened it was like ... All your exercises and all your routines and everything you can’t do anymore. So it’s just a whole new lifestyle. (Emma, age 42, interview)

So, I had to change my, I stopped playing squash about seven/eight years ago. I stopped jogging at the same time. (Chata, age 65 , interview)

Well, if I could just say, it's definitely slowed me down. I'm way less active than I used to be. (Laila, age 60, focus group 3)

It gets worse when I exercise more, so I don't do those particular exercises. (Davis, age 61, focus group 5)

\section{Social Disruption}

I've been out with her and other friends and they'll be two blocks ahead of me and I can only walk as fast as I can walk and they don't turn around to look... and I'm left out. (Audrey, age 63, interview)

I used to play hockey with him [son]. I can't do it. Ball hockey, now l'd break my neck you know. But I can't run around and do the ball hockey and soccer and stuff so it's kind of discouraging and my husband's gone a lot with his work so I'm the one that plays sports with him. (Anna, age 50, focus group 1)

So what happens is I work for my family business in fruits and veggies and then the truck comes in. There's a least two guys have to be unloading and just stack it up in the back. And when I know the pain's going to come, I get extra people. I put two more people. So that's definitely a change. (Max, age 48, focus group 2)

Focus group 4:

Safa (age 38): My gym friends, I used to go and work out with them. I stopped going there, so they are not [friends] anymore. We don't have connections at the same thing.

Moderator: Anyone else have an example?

Isabel (age 48): Unfortunately, my family is not that active...They want to get together but they want to rest and socialize. They don't say, let's go for a walk, let's go for a run, let's go be active.

\section{Emotional Disruption}

I got quite depressed. Suddenly I was overwhelmed with this feeling of I'm only 60-whatever-I-was at the time. We're very long-lived in my family, oh my god, is this the beginning of the next 30 years? (Jean, age 65 , focus group 1)

I feel out of shape and I feel that I've put on extra weight that I normally wouldn't have. I'm not as active as I'd like to be. And I feel like now I'm 42 and I feel like this is the time in my life when I need to be doing these things and yet I'm having trouble doing them. So I almost feel a bit cheated, like this is not the right time to get this. (James, age 42, interview)

Altered Way of Thinking about Body and Self

\section{Altered Sense of Self}

I pretend I don't have a knee problem. People ask me, l'm fine. And l'll go l'll hobble and then people say Nigel, are you limping? No, l'm fine. So I want to be in denial because my job, my day job requires that I be performing and you can't show this potential weakness. (Nigel, age 61 , focus group 3 )

I'm a bad mom because I can't look after my kids the way I want to when my leg was really bad. (Rebecca, age 37, interview)

I would not be seen in any of my dancing clothes with this extra 70 pounds on because it just doesn't feel right. I used to love getting dressed up and wearing a nice pair of heels and wearing a nice outfit and going out and you know, kicking up my feet. (Susan, age 47, interview)

\section{A New Awareness}

I may have to think about going up a ladder, whereas before, I used to go 'up' a ladder... It's changed my way of thinking, more than trying to reduce the activity because I still think I can do it. (Adam, age 54 , interview)

And, when I'm walking or if I have to run for any reason, I'Il take shorter strides. I feel that if, I read somewhere if you take long strides, it's putting a lot of tension on the knee because of where you're striking. So l'll make a mental effort to not stretch my strides out too much. ( James, age 42, interview)

Lack of Trust in the Knee

I'm nervous sometimes. I'm scared to take a step because I'm like what if it just bends in half the other way and I'm just stuck here? (Lynn, age 43, focus group 6)

Standing up first thing in the morning when I get out of bed, I have to push myself up because I don't trust my knees. (Davis, age 61 , focus group 5)

and the impact on their lives. For example, Emma (age 42, interview) recounted: "I was running and doing all kinds of sports and very skinny so it's caused a little bit of depression trying to manage everything and not being able to do everything I used to".

Participants also expressed concerns about the future. They worried about knee symptoms getting worse. Older adults expressed concerns about maintaining independence as they aged. Participants also expressed concerns about how changes in their physical activity would affect their general health. For example, a participant who reported she had decreased her activity and gained weight due to her knee, commented: "If I can't get this weight off, it's a real threat that I may end up insulin dependent, and with that comes all kinds of other associated risks". (Susan, age 47, interview) 


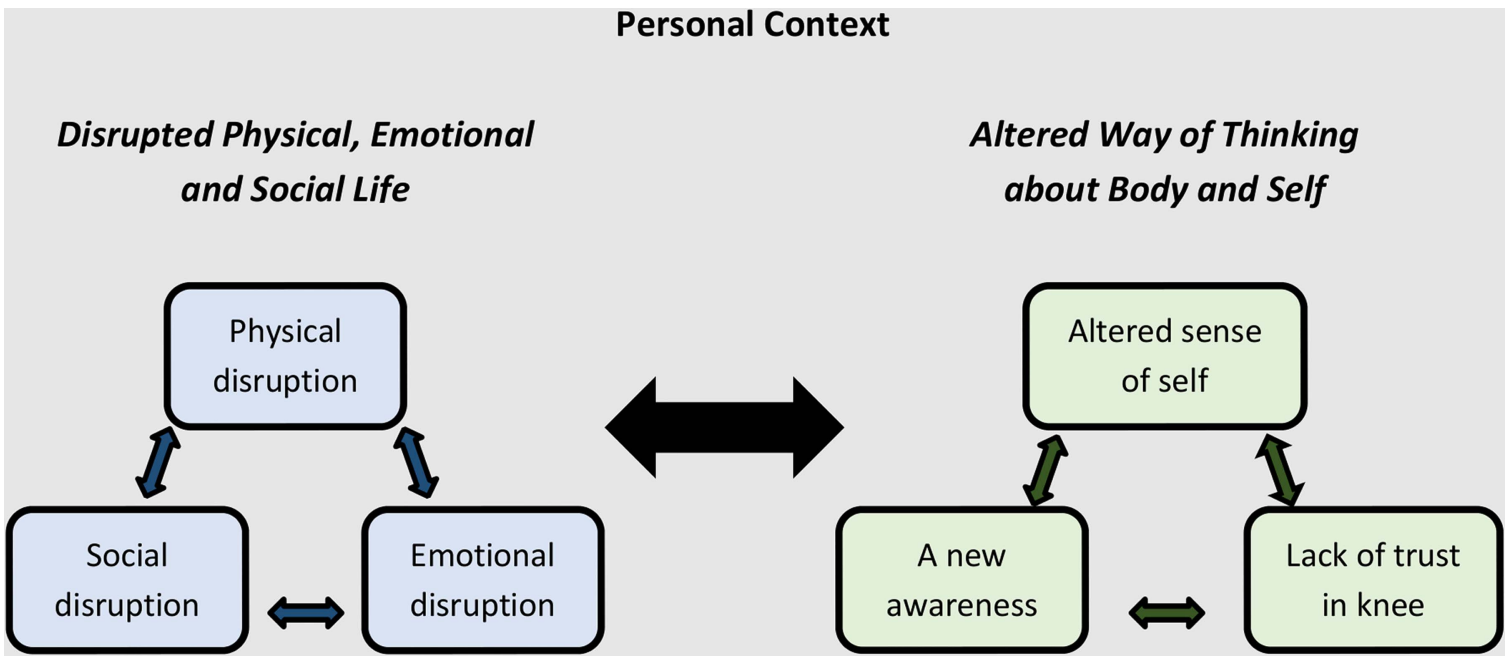

Figure 1 Core category: disruption and change. Under the core category, two main categories of disruption and change were generated: (1) Disrupted physical, social and emotional life, which includes three aspects of disruption: physical disruption, emotional disruption and social disruption; and (2) An altered way of thinking about the body and self, which includes changes in how people thought about their bodies (a new awareness and a lack of trust in their knee) and an altered sense of self. The arrows indicate the potential reciprocal influences within categories and across these categories. The role of personal context is indicated by situating the categories within the person's individual context.

\section{Altered way of thinking about the body and self Altered sense of self}

Participants described changes in the way they viewed themselves. They talked about the physical changes which made them feel they were no longer 'infallible'. Men, in particular, recounted that they once felt 'strong' and 'capable', but knee symptoms made them feel less capable. For instance, Peter (age 57, focus group 1) stated: "All of sudden you start thinking, I can't do this anymore, and you extrapolate from the physical to the other things...You start to think that ... you're not as good as you used to be". Some women also reported that symptoms undermined their view of themselves as active and independent.

The effect of symptoms on aspects of participants' lives, such as social roles, influenced participants' appraisals of themselves. For instance, some participants' view of themselves as parents changed. This change was more commonly recounted by mothers. One participant stated she was a 'bad mom' because she could not take care of her children the way she wanted to. Another woman explained that she was not a good role model to her children as she was not leading a physically active lifestyle.

Changes in appearance were also linked to sense of self, particularly for women. A common example recounted by women was not being able to wear 'nice' shoes. While this was often downplayed as a minimal consequence, it was disheartening to participants and threatened their identity. For example, Rebecca (age 37, interview) commented: "It makes me feel like crap. I can never be cute... I can't wear shoes and definitely not high heels...". Another woman described the weight gain she associated with her knee symptoms as "a huge blow to my self-esteem”. (Susan, age 47, interview)

The visibility of symptoms, or lack thereof, affected how participants believed others perceived them. Some participants spoke of not wanting to appear 'disabled' or 'weak' to others and recounted trying to hide their knee symptoms. Max (age 48, focus group 2) explained: "You don't want to be seen as a nearly handicapped or a not fully physically functioning individual, so you want to sometimes try to avoid these social situations". In contrast, other participants spoke of the invisibility of symptoms as a challenge because people underestimated the consequences of symptoms. For example, one woman recounted feeling that work colleagues did not understand why she had special considerations such that she could work from home.

\section{A new awareness}

Participants indicated they had a new awareness of their body as a consequence of having knee symptoms. Universally, participants recalled not thinking about their knees prior to having symptoms. After the onset of symptoms, their knee came to the fore of their consciousness and they became very aware of having a knee. Some participants reported that their knee seemed to always be on their mind. One woman recounted: "It's just that I am constantly aware, thinking twice with every activity... Everything now has now a new think to it" (Gail, age 60, focus group 5). With this new consciousness, participants recounted being more deliberate and cautious in moving their legs. They reported that they thought about if and how to perform movements. One participant explained: "I have to be more conscious and 
think about how I'm moving and speed of changing direction and how I use my legs" (Oscar, age 59, interview). Performing activities that were once taken for granted, unconscious acts often became more conscious movements. Other conscious acts included avoiding activities, planning activities ahead or 'slowing' down.

While some participants indicated that the heightened awareness of their knee became more subconscious over time, most indicated that this awareness persisted to some extent.

\section{Lack of trust in knee}

Participants recounted unpredictable symptoms of pain, giving way and locking. As a result of the perceived lack of control, they reported that they did not trust their knee, sometimes characterising it as a 'liability'. They indicated that the knee had let them down or 'betrayed' them. For example, during an exchange between participants in a focus group, Laila (age 60, focus group 3) stated: "So I don't trust that I could go jogging anymore or anything like that...because I don't think I'd make it. I think that knee would go". Another participant responded: "I have that feeling too. If I was coming home and it was dark and somebody was following me down the street, could I peel out of here...? Could I trust my knees to do that?" (Donna, age 56, focus group 3).

\section{DISCUSSION}

This paper illustrates the significant and varied consequences knee symptoms had on the lives of adults who were relatively young with mild-to-moderate knee symptoms. While previous studies reported disruption in the lives of older adults with OA, often over age 60, little was known about the consequences of knee symptoms in younger adults. This study found that younger adults experienced a range of significant disruptions and changes, shaped by their personal context. Participants reported disruption and change in their physical, social and emotional life as well as an altered way of thinking about their body and selves. Our findings underscore the importance of recognising the consequences of knee symptoms in younger adults in order to develop health and community based supports to address peoples' complex needs. Our findings also provide insight into previous research which showed that people with knee symptoms were proactive in working to manage symptoms. ${ }^{26}$ People may have been motivated to work hard to find ways to manage symptoms due to the significant disruption and change that resulted from symptoms (eg, disruption in physical activity).

In the current sample, a common consequence discussed by participants was change in physical activities. In other research, findings demonstrated that people with arthritis were less likely to be physically active than those without arthritis. ${ }^{37}$ We found that participants gave up demanding physical activities and changed how, or how much, they performed activities. Changes in physical activity had important consequences for participants' well-being. Moreover, reduced physical activity could have long-term effects on participants' health and well-being as they age. Physical activity has been associated with reduced risk of chronic disease and premature death, with some research showing that mid-life physical activity increased healthy aging, disability-free survival and self-reported health. ${ }^{38}$ Recent research also found that people with OA had an increased risk of cardiovascular disease, which may in part be related to activity levels. $^{39}$

Participants experienced a myriad of disruptions in their social life (leisure, work, family), highlighting the consequences knee symptoms had on activities and relationships that enrich lives and have been shown to predict well-being. ${ }^{40}$ Disruptions to social life have been reported in other research in chronic disease ${ }^{17}$ and with older adults with OA, who described changes in social interactions, recreation, work and travel. ${ }^{21}{ }^{41-43}$ Research in younger adults with $\mathrm{OA}$ is limited but others have also reported an effect on work ${ }^{24}{ }^{44}$ and social activities. ${ }^{44}$ In a study with a sample of younger people with OA who were mainly labourers, participants reported a reduction in work and family income. ${ }^{45}$ In comparison, our sample had few participants who were working in manual labour, which may have underestimated the potential consequences on work as participants may have been less likely to give up work.

Sociological literature has highlighted the 'loss of self' experienced with chronic conditions. ${ }^{17}{ }^{18}$ Research in older adults with OA indicated that peoples' self-worth was reduced as they felt less valuable physically. ${ }^{41}$ Studies of former athletes with OA found people reported changes in identity from the loss of athletic roles and physical changes. ${ }^{43}{ }^{46}$ Similarly, in our study when changes conflicted with participants' expectations of themselves, people experienced an altered sense of self. Underlying the changes was a loss of part of their identity. Future work is needed to understand how people cope with these changes and how healthcare professionals can best provide support to individuals.

This study also extends findings from previous research on how people think about their knee. In our study, participants recounted a new awareness and lack of trust in their knee. In previous research, Maly ${ }^{47}$ indicated that younger adults with knee symptoms engaged in 'being careful', a process aimed at avoiding knee damage during physical activity. Our findings suggest that people had a new way of thinking about the knee that permeated their lives and influenced actions. One can view these changes through Gadow's conceptualisation of embodiment. ${ }^{48}$ Gadow described the lived body as the experience of unity between the body and self when people do not think about their body. After an injury/ illness, there is a stage of disunity between body and self, object body, in which there is a heightened awareness of the body part. ${ }^{48}$ Our participants described this transition from taking their knee for granted to being very 
conscious of their knee. In Gadow's theory, people move on to learn to live with their injury/illness and even find meaning in their body. ${ }^{48}$ While our participants recounted adaptations to live with their knee, a heightened awareness of their knee persisted.

Participants indicated that part of 'a new awareness' was thinking about how to perform movements and being more deliberate in moving their legs. Whether people changed the way they moved is less clear and the implications of any conscious changes in movement patterns for the knee or other joints are unknown. Other researchers have postulated that biomechanical aberrations that persist over time may have important consequences for structural changes in the joint. ${ }^{49}$ For instance, disruption of normal gait mechanics (eg, with trauma, weight gain) can shift the loading patterns during weight-bearing activity to cartilage regions not well adapted for those loads. ${ }^{50-52}$ It is postulated that at some point the cartilage can no longer adapt to the altered ambulatory loading and begins to degrade, increasing the rate of OA progression. ${ }^{53}$ While more research is needed to understand how peoples' heightened awareness of their knee affects movement, our findings indicate that people may benefit from support to regain confidence in their knee and to ensure that people are making appropriate adaptations to address symptoms that do not increase risk for joint deterioration.

Our findings have implications for policy and practice. First, given the consequences of knee symptoms on physical activity, interventions are needed to help younger adults with knee symptoms remain physically active in valued activities by appropriately modifying their actions when needed and by facilitating exercising in ways that prevent excessive joint stress. Engaging in appropriate physical activity can reduce knee symptoms, ${ }^{54-56}$ and may delay disease progression and affect peoples' health more generally by preventing comorbidity. Second, participants' accounts revealed that consequences extended beyond the physical to social life and how one views him/herself. These consequences deserve increased attention and support in clinical practice. Finally, our findings suggest symptoms and their consequences cannot be separated from other aspects of the person in the context of their life. We found variation in experiences within categories based on participants' personal context, such as gender, timing (age, stage of life), priorities (eg, type/value of activities), and the nature of social roles (eg, demands of work, family). There is a need for clinicians to tailor advice and support to an individual's needs considering their symptoms, the consequences of symptoms on their lives and their personal context.

The findings of this study need to be considered within the limitations of the work. We used a self-report diagnosis of OA or OA-like knee symptoms. We based our joint symptoms question on a widely used survey question on joint pain ${ }^{57}$ and used carefully selected exclusion criteria to recruit participants who were more likely to have OA. Prior research indicates that knee pain is often the first sign of knee OA and is a predictor of future radiographic OA. ${ }^{58}$ Moreover, OA often coexists with other knee conditions. ${ }^{60-62}$ For instance, recent research found that underlying radiographic OA was highly prevalent in middle-aged and older adults with a clinical diagnosis consistent with chronic patellofemoral pain. ${ }^{61}$ However, we acknowledge that there is a chance that some participant's knee symptoms could have been the result of conditions other than OA. The majority of participants in our sample were working, had a postsecondary education, and lived in an urban area. It is possible these factors influenced their experience with symptoms. Participants were not sampled based on ethnicity and future work is needed to explore the role of culture in understanding the consequences of knee symptoms. In addition, only one researcher conducted the focus groups and interviews and coded the data. There is the potential that this could limit alternative interpretations of the data and competing explanations. To mitigate this, all authors were involved in interrogating the data when reviewing the transcripts and participating in regular group discussions. Finally, qualitative methods allowed us to develop concepts that helped us to understand individuals' experiences with knee symptoms. Further work would be needed to investigate the transferability of our findings to the population of adults aged 35-65 years with knee symptoms.

\section{CONCLUSION}

While OA has often been thought of as an 'old' person's disease and clinical practice has focused on older adults, this study illuminates the significant disruption and change experienced by 35-65-year-olds with knee symptoms. The range of consequences experienced by younger adults with knee symptoms was similar to consequences reported in the literature on older adults with OA; yet, these consequences in younger adults with knee symptoms may be underappreciated in clinical practice. These findings support calls for a paradigm shift in OA management towards early intervention. They also draw attention to the need for approaches in the healthcare system or community which support the diverse needs of the individual in the context of their lives. In particular, support is needed to help people remain physically active as they age. Future research is needed to examine how to best support younger adults with $\mathrm{OA}$ symptoms and address the consequences of symptoms on their lives.

\section{Author affiliations}

${ }^{1}$ Division of Health Care and Outcomes Research, Toronto Western Research Institute, Toronto, Ontario, Canada

${ }^{2}$ Institute of Medical Science, University of Toronto, Toronto, Ontario, Canada ${ }^{3}$ Department of Physical Therapy, University of Toronto, Toronto, Ontario, Canada

${ }^{4}$ Institute of Health Policy, Management and Evaluation, University of Toronto, Toronto, Ontario, Canada 
${ }^{5}$ Toronto Rehabilitation Institute, University Health Network, Toronto, Ontario, Canada

${ }^{6}$ Mobility Program Clinical Research Unit, Li Ka Shing Knowledge Institute, St. Michael's Hospital, Toronto, Ontario, Canada

${ }^{7}$ Dalla Lana School of Public Health, University of Toronto, Toronto, Ontario, Canada

Contributors CM contributed to the conception and design of the study, conducted the focus groups and interviews, contributed to the analysis and interpretation of the data and took primary responsibility for drafting the manuscript. SBJ, JS, EMB and AMD contributed to the conception and design of the study, contributed to the analysis and interpretation of the data and revised the manuscript for critically important intellectual content. All authors approved the final version of the manuscript.

Funding CM was supported by a Fellowship from the Canadian Institutes of Health Research.

Competing interests None.

Ethics approval University Health Network Research Ethics Board.

Provenance and peer review Not commissioned; externally peer reviewed.

Data sharing statement No additional data are available.

Open Access This is an Open Access article distributed in accordance with the Creative Commons Attribution Non Commercial (CC BY-NC 4.0) license, which permits others to distribute, remix, adapt, build upon this work noncommercially, and license their derivative works on different terms, provided the original work is properly cited and the use is non-commercial. See: http:// creativecommons.org/licenses/by-nc/4.0/

\section{REFERENCES}

1. Badley EM. The effect of osteoarthritis on disability and health care use in Canada. J Rheumatol Suppl 1995;43:19-22.

2. Bitton R. The economic burden of osteoarthritis. Am J Manag Care 2009;15(8 Suppl):S230-5

3. Creamer P, Hochberg MC. Osteoarthritis. Lancet 1997;350:503-8.

4. Litwic A, Edwards MH, Dennison EM, et al. Epidemiology and burden of osteoarthritis. Br Med Bull 2013;105:185-99.

5. Murphy L, Helmick CG. The impact of osteoarthritis in the United States: a population-health perspective. Am J Nurs 2012;112 (3 Suppl 1):S13-19.

6. Power JD, Badley EM, French MR, et al. Fatigue in osteoarthritis: a qualitative study. BMC Musculoskelet Disord 2008;9:63.

7. Lawrence RC, Felson DT, Helmick CG, et al. Estimates of the prevalence of arthritis and other rheumatic conditions in the United States. Part II. Arthritis Rheum 2008;58:26-35.

8. Nguyen US, Zhang Y, Zhu Y, et al. Increasing prevalence of knee pain and symptomatic knee osteoarthritis: survey and cohort data Ann Intern Med 2011:155:725-32.

9. Sharma L, Kapoor D, Issa S. Epidemiology of osteoarthritis: an update. Curr Opin Rheumatol 2006;18:147-56.

10. Kopec JA, Rahman MM, Berthelot JM, et al. Descriptive epidemiology of osteoarthritis in British Columbia, Canada $J$ Rheumatol 2007;34:386-93.

11. Losina E, Weinstein AM, Reichmann WM, et al. Lifetime risk and age at diagnosis of symptomatic knee osteoarthritis in the US. Arthritis Care Res (Hoboken) 2013:65:703-11.

12. Canadian Institute for Health Information. Hip and Knee Replacements in Canada-Canadian Joint Replacement Registry 2008-2009 Annual Report. 2009. https://secure.cihi.ca/estore/ productFamily.htm?pf=PFC1063\&lang=en\&media $=0$.

13. Losina $\mathrm{E}$, Thornhill TS, Rome BN, et al. The dramatic increase in total knee replacement utilization rates in the United States cannot be fully explained by growth in population size and the obesity epidemic. J Bone Joint Surg Am 2012;94:201-7.

14. Hunter DJ. Lower extremity osteoarthritis management needs a paradigm shift. Br J Sports Med 2011;45:283-8.

15. United States Bone and Joint Initiative. Report of the May 2012 Chronic Osteoarthritis Management Initiative (COAMI) Work Group Meeting and Call to Action. 2012.

16. Murray SA, Kendall M, Carduff E, et al. Use of serial qualitative interviews to understand patients' evolving experiences and needs. BMJ 2009:339:b3702.
17. Bury M. Chronic illness as biographical disruption. Sociol Health IIIn 1982;4:167-82.

18. Charmaz K. Loss of self: a fundamental form of suffering in the chronically ill. Sociol Health IIIn 1983;5:168-95.

19. Lawton J. Lay experiences of health and illness: past research and future agendas. Sociol Health IIIn 2003;25:23-40.

20. Pierret J. The illness experience: state of knowledge and perspectives for research. Sociol Health IIIn 2003;25:4-22.

21. Sanders C, Donovan J, Dieppe P. The significance and consequences of having painful and disabled joints in older age: co-existing accounts of normal and disrupted biographies. Sociol Health IIIn 2002;24:227-53.

22. Atkin K, Ahmad W. Pumping iron: compliance with chelation therapy among young people who have thalassaemia major. Sociol Health IIIn 2000;22:500-24.

23. Guccione AA, Felson DT, Anderson JJ, et al. The effects of specific medical conditions on the functional limitations of elders in the Framingham Study. Am J Public Health 1994;84:351-8.

24. Kao MH, Tsai YF. Living experiences of middle-aged adults with early knee osteoarthritis in prediagnostic phase. Disabil Rehabil 2012;34:1827-34

25. Alami S, Boutron I, Desjeux D, et al. Patients' and practitioners views of knee osteoarthritis and its management: a qualitative interview study. PLoS One 2011;6:e19634

26. Mackay C, Badley EM, Jaglal SB, et al. "We're All looking for solutions": a qualitative study of the management of knee symptoms. Arthritis Care Res (Hoboken) 2014;66:1033-40.

27. Charmaz K. Constructing grounded theory: a practical guide through qualitative analysis. Thousand Oaks: Sage Publications Inc., 2006.

28. Morse J, Stern P, Cordin J, et al. Developing grounded theory: the second generation. 1st edn. Walnut Creek, CA: University of Arizona Press, 2009.

29. Coyne IT. Sampling in qualitative research. Purposeful and theoretical sampling; merging or clear boundaries? J Adv Nurs 1997;26:623-30.

30. Lambert SD, Loiselle CG. Combining individual interviews and focus groups to enhance data richness. J Adv Nurs 2008;62. 228-37.

31. Tracy SJ. Qualitative quality: eight "Big-Tent" criteria for excellent qualitative research. Qualitative Inquiry 2010;16:837-51.

32. Roos EM, Lohmander LS. The Knee injury and Osteoarthritis Outcome Score (KOOS): from joint injury to osteoarthritis. Health Qual Life Outcomes 2003;1:64.

33. Corbin J, Strauss A. Basics of qualitative research. 3rd edn Thousand Oaks: Sage Publications, Inc, 2008.

34. Reynolds J, Kizito J, Ezumah N, et al. Quality assurance of qualitative research: a review of the discourse. Health Res Policy Syst 2011;9:43.

35. Elliott N, Lazenbatt A. How to recognise a 'quality' grounded theory research study. Aust J Adv Nurs 2005;22:48-52.

36. de Groot IB, Favejee MM, Reijman M, et al. The dutch version of the knee injury and osteoarthritis outcome score: a validation study. Health Qual Life Outcomes 2008;6:16.

37. Hootman JM, Macera CA, Ham SA, et al. Physical activity levels among the general US adult population and in adults with and without arthritis. Arthritis Rheum 2003;49:129-35.

38. Sun Q, Townsend MK, Okereke OI, et al. Physical activity at midlife in relation to successful survival in women at age 70 years or older. Arch Intern Med 2010;170:194-201.

39. Rahman MM, Kopec JA, Anis AH, et al. Risk of cardiovascular disease in patients with osteoarthritis: a prospective longitudinal study. Arthritis Care Res (Hoboken) 2013;65:1951-8.

40. Umberson D, Montez JK. Social relationships and health: a flashpoint for health policy. J Health Soc Behav 2010;51(Suppl): S54-66.

41. Maly MR, Krupa T. Personal experience of living with knee osteoarthritis among older adults. Disabil Rehabil 2007;29:1423-33.

42. Ong BN, Jinks C, Morden A. The hard work of self-management: living with chronic knee pain. Int J Qual Stud Health Well-being 2011;6:7035.

43. Turner A, Barlow J, Ilbery B. Play hurt, live hurt: living with and managing osteoarthritis from the perspective of ex-professiona footballers. J Health Psychol 2002;7:285-301.

44. Gignac MA, Davis AM, Hawker G, et al. "What do you expect? You're just getting older": a comparison of perceived osteoarthritis-related and aging-related health experiences in middleand older-age adults. Arthritis Rheum 2006;55:905-12.

45. Kao MH, Tsai YF. Illness experiences in middle-aged adults with early-stage knee osteoarthritis: findings from a qualitative study. J Adv Nurs 2014;70:1564-72. 
46. Keysor JJ, Sparling JW, Riegger-Krugh C. The experience of knee arthritis in athletic young and middle-aged adults: an heuristic study. Arthritis Care Res 1998;11:261-70.

47. Maly MR, Cott CA. Being careful: a grounded theory of emergent chronic knee problems. Arthritis Rheum 2009;61:937-43.

48. Gadow S. Body and self: a dialectic. J Med Philos 1980;5: 172-85.

49. Roos EM, Herzog W, Block JA, et al. Muscle weakness, afferent sensory dysfunction and exercise in knee osteoarthritis. Nat Rev Rheumatol 2011;7:57-63.

50. Andriacchi TP, Mundermann A, Smith RL, et al. A framework for the in vivo pathomechanics of osteoarthritis at the knee. Ann Biomed Eng 2004;32:447-57

51. Andriacchi TP, Koo S, Scanlan SF. Gait mechanics influence healthy cartilage morphology and osteoarthritis of the knee. J Bone Joint Surg Am 2009;91(Suppl 1):95-101.

52. Vincent KR, Conrad BP, Fregly BJ, et al. The pathophysiology of osteoarthritis: a mechanical perspective on the knee joint. Phys Med Rehabil 2012;4:S3-9.

53. Andriacchi TP, Mundermann A. The role of ambulatory mechanics in the initiation and progression of knee osteoarthritis. Curr Opin Rheumatol 2006;18:514-18.

54. Bennell KL, Hinman RS. A review of the clinical evidence for exercise in osteoarthritis of the hip and knee. J Sci Med Sport $2011 ; 14: 4-9$.
55. Conn VS, Hafdahl AR, Minor MA, et al. Physical activity interventions among adults with arthritis: meta-analysis of outcomes. Semin Arthritis Rheum 2008;37:307-16.

56. Roddy $\mathrm{E}$, Zhang W, Doherty M. Aerobic walking or strengthening exercise for osteoarthritis of the knee? A systematic review. Ann Rheum Dis 2005;64:544-8.

57. Centres for Disease Prevention and Control. QuickStats: percentage of adults reporting joint pain and stiffness-a National Health Interview Survey, United States, 2006. MMWR 2013;57:467.

58. de Klerk BM, Willemsen S, Schiphof D, et al. Development of radiological knee osteoarthritis in patients with knee complaints. Ann Rheum Dis 2012;71:905-10.

59. Thorstensson CA, Andersson ML, Jonsson $\mathrm{H}$, et al. Natural course of knee osteoarthritis in middle-aged subjects with knee pain: 12-year follow-up using clinical and radiographic criteria. Ann Rheum Dis 2009;68:1890-3.

60. Hill CL, Gale DR, Chaisson CE, et al. Periarticular lesions detected on magnetic resonance imaging: prevalence in knees with and without symptoms. Arthritis Rheum 2003;48:2836-44.

61. Hinman RS, Lentzos J, Vicenzino B, et al. Is patellofemoral osteoarthritis common in middle-aged people with chronic patellofemoral pain? Arthritis Care Res (Hoboken) 2014;66:1252-7.

62. Picerno V, Filippou G, Bertoldi I, et al. Prevalence of Baker's cyst in patients with knee pain: an ultrasonographic study. Reumatismo 2013;65:264-70. 